\title{
Revista Brasileira de Enfermagem REBEn \\ A prática pedagógica das professoras de enfermagem e os saberes
}

PESQUISA

\author{
The pedagogical practice of nursing teachers and their knowledge \\ Lá práctica pedagógica de las maestras de enfermería y los conocimientos
}

\section{Maria Zélia de Araújo Madeira}

Enfermeira. Mestre em Educação. Docente do Curso de Graduação em Enfermagem da Universidade Federal do Piauí, Teresina, PI

e da Faculdade de Saúde, Ciências Humanas e Tecnológicas do Piauí (NOVAFAPI).

zeliamadeira15@yahoo.com.br.

\section{Maria da Glória Soares Barbosa Lima}

Doutora em Educação e Professora dos Cursos de Graduação e do Programa de Pós-Graduação em Educação pela UFPI, Teresina, PI. glloriasoares@yahoo.com.br

Retirado da dissertação intitulada: A prática pedagógica das professoras do curso de enfermagem: revisitando a construção dos saberes docentes, defendida junto ao Programa de Mestrado em Educação da UPFI, em agosto de 2006 .

\section{RESUMO}

Este artigo tem como objetivos investigar os saberes docentes que alicerçam a prática pedagógica dos enfermeiros-professores, vislumbrando entender o significado dessa prática social no que refere ao processo de tornar-se professor de profissão. 0 estudo de natureza qualitativa, com ênfase metodológica na História Oral, tendo como instrumentos de recolha de dados entrevistas semi-estruturadas, e a análise de dados a partir da análise de conteúdo. Dentre as constatações reveladas pelas análises, evidencia-se que os saberes docentes e a prática pedagógica incidem positivamente para a consolidação do processo de tornar-se professor de profissão no âmbito da docência no curso de enfermagem da UFPI. Descritores: Ensino; Educação em enfermagem; Docente de enfermagem

\section{ABSTRACT}

This article has as objectives investigate the faculty knowledge that embase the pedagogical practice of the nursing-professors, glimpsing to understand the meaning of this social practice in what it refers to the process to become a professional professor. The qualitative nature study, with methodological emphasis in verbal story, used as instruments of data collection semi-arranged interviews, and the data analysis starting from the content analysis. Among the results obtained from the analysis, it has proven that the faculty knowledge and the pedagogical practice positively incises for the consolidation of the process to become professional professor in the scope of the faculty in the nursing course at UFPI.

Descriptors: Teaching; Nursing education; Faculty, nursing.

\section{RESUMEN}

Este artículo tiene como objetivos investigar los conocimientos docentes que sostienen la práctica pedagógica de los enfermeros-profesores, vislumbrando entender el significado de esa práctica social en lo que se refiere al proceso de tornarse profesor de profesión. El estudio de naturaleza cualitativa, con énfasis metodológica en la Historia Oral, teniendo como instrumentos de levantamiento de datos entrevistas semiestructuradas y el análisis de datos a partir del análisis de contenido. Dentro de las constataciones reveladas por los análisis, se evidencia que los conocimientos docentes y la práctica pedagógica inciden positivamente para la consolidación del proceso de tornarse profesor de profesión en el ámbito de la docencia en el curso de enfermería de la UFPI.

Descriptores: Enseñanza; Educación en Enfermería; Docente de Enfermería.

Madeira MZA, Lima MGSB. A prática pedagógica das professoras de enfermagem e os saberes. Rev Bras Enferm 2007 jul-ago; 60(4):400-4.

\section{INTRODUÇÃO}

Refletir sobre a prática pedagógica nos remete à formação no âmbito dos cursos de enfermagem uma vez que estes vêm repensando seu modelo de formação, mais intensamente desde as últimas décadas do século XX até o momento, colocando em evidência a atual situação do mercado de trabalho, as competências necessárias ao pessoal de enfermagem de nivel médio e superior, o processo de mobilização e participação nas entidades de classe e o seu papel na implementação do Sistema Único de Saúde - SUS.

Desse modo, nossa investigação foi guiada pela busca dos seguintes objetivos: investigar os saberes que fundamentam a prática, identificar os saberes mobilizados, descrever a prática pedagógica, e analisar as contribuições dos saberes da docência na prática pedagógica dos professores do curso de Enfermagem.

A prática pedagógica ${ }^{(1)}$ deve permitir que os próprios professores transmitam uma imagem de pessoas que sabem o que fazem e que dominam as situações por meio da razão e da lucidez total, dissimulando, sempre que necessário, esconderia seus truques para manipular os alunos, seus tiques, deslizes verbais,
Submissão: $03 / 05 / 2007$

Aprovação: 10/07/2007 
cóleras, momentos de dúvidas.

Reportando-nos ao campo da enfermagem, a trajetória das práticas pedagógicas dominantes, ao longo do tempo, em muitos cursos nessa área denuncia o predomínio de um modelo tradicional, que nem sempre possibilita uma formação crítica e reflexiva dos profissionais. No entanto, nesse campo, já se mostra visível um movimento no sentido da superação de paradigmas que colaboram com a reprodução do modelo social vigente, que, via de regra, tem se mostrado, cada vez mais, excludente e, portanto, incompatível com as demandas da sociedade da informação e do conhecimento(2).

Assim, as novas demandas para o ensino e aprendizagem na área de enfermagem apontam para uma perspectiva interdisciplinar de diálogo com outras áreas de conhecimento, o que implica, necessariamente, o abandono, a saída de um sistema estanque cartesiano de departamentalizar os diferentes saberes, revelando a possibilidade de desenvolvimento de uma nova prática educativa em enfermagem, assim como em outras esferas educacionais, mais comprometida com a sociedade e, necessariamente, mais igualitária.

Tem se tornado patente que, na realidade do curso de Enfermagem, emerge a compreensão de que o processo da prática reflexiva entre enfermeiros-docentes, à semelhança do que ocorre em outras áreas profissionais, também tem merecido muitas discussões e algumas pesquisas em nosso meio, principalmente pela constatação da necessidade de reflexões filosóficas e reencaminhamentos didático-metodológicos que venham atender às expectativas da cultura pedagógica postulada para o novo milênio, conforme estabelecido na LDB 9394/1996, no capítulo IV, art. 43, que "dentre as finalidades principais da educação superior, destaca a necessidade de se estimular à formação de profissionais capazes de exercitar o espirito científico e o pensamento reflexivo".

O fenômeno educacional, neste âmbito, visto e compreendido numa dimensão ampliada, abrangente, pode ser definido como o conjunto de processos de formação e de aprendizagem socialmente elaborados e destinados a instruir os membros da sociedade. $O$ conjunto dos educadores que asseguram esses processos educativos é, então, chamado a definir sua prática em relação aos saberes que possuem e transmitem. A relação dos docentes $^{(3)}$ com os saberes não se reduz à função de transmissão dos conhecimentos constituídos, considera-se que suas práticas integram diferentes saberes, tendo em vista que o saber docente é, sobretudo, um saber plural. Ou seja, compreende diferentes tipologias, profunda complexidade e um caráter polissêmico.

Os saberes docentes ${ }^{(4)}$ são temporais, plurais e heterogêneos, ecléticos e sincréticos, personalizados e situados. São temporais porque resultam de um processo longo de construção através do tempo, como as aprendizagens realizadas durante a longa vida escolar. Sendo que as aprendizagens dos primeiros anos de trabalho possuem uma importância estratégica muitas vezes desconsiderada. Os saberes são temporais também porque se desenvolvem no âmbito de uma carreira, de um processo de vida profissional de longa duração, do qual fazem parte dimensões identitárias e de socialização profissional.

A pluralidade e a heterogeneidade dos saberes docentes significa que provêm de diversas fontes; são também ecléticos e sincréticos porque não formam um repertório unificado em torno de uma teoria: os professores utilizam muitas teorias, concepções e técnicas, de acordo com as necessidades de trabalho, mesmo que elas pareçam, às vezes, contraditórias para os pesquisadores universitários. Aunidade dos saberes dos professores é dada pela ação, pelas necessidades e especificidades da prática.

A pluralidade de que se revestem esses saberes advém de um composto variado que compreende conhecimentos, experiências e vivências, daí a compreensão de que são heterogêneos e plurais por serem constituídos dos saberes das disciplinas, dos saberes curriculares, dos saberes da formação profissional e dos saberes da experiência ${ }^{(3)}$.

Os saberes disciplinares ou de conteúdos, constituem-se em saberes sociais pré-determinados, que, selecionados, pelas instituições formadoras, integram-se à prática docente. Os saberes curriculares correspondem aos discursos, objetivos, conteúdos e métodos e apresentam-se, concretamente, em forma de programas escolares. Os saberes profissionais ou pedagógicos referem-se a conhecimentos ligados às ciências da educação, destinados à formação dos professores, incluem desde teorias a métodos pedagógicos. $E$ os saberes experienciais - dizem respeito àqueles saberes que os professores constroem e põem em prática tendo como base seu trabalho cotidiano e conhecimento do seu meio ${ }^{(3)}$.

Desse modo, dizemos que o professor, um profissional do saber, é alguém que domina determinados saberes, que, em dada situação, é capaz de transformar e conferir novas configurações a esses saberes e, ao mesmo tempo, assegurar a dimensão ética peculiar a esses saberes que dão suporte à práxis no cotidiano do seu trabalho, vislumbrando o crescimento da escola, da aprendizagem do alunado e seu próprio crescimento profissional(5).

Para tanto, o professor deve ser capaz de assimilar e exercitar, também, os saberes da tradição pedagógica, e, aliada a esses saberes, deve possuir uma competência cultural, que o capacite discutir com os alunos, ser autêntico, administrar a classe e mediar a aprendizagem do alunado, bem como identificar comportamentos e contribuir para modificá-los, se necessário for. Portanto, 0 "saber ensinar" comporta uma pluralidade de saberes, caracterizando-se como um reservatório onde o professor busca, para efetivar sua razão prática, razões, argumentos e julgamentos ${ }^{(6)}$.

Assim, o desafio da gestão pedagógica e da transformação pedagógica da matéria em situações reais de prática e de tomada de decisão na sala de aula ou em outros espaços educativos conduz o professor a gerar ou produzir saberes quando articula adequada e criativamente seu reservatório de saberes num determinado contexto de interação com outros sujeitos (alunos), na ecologia da classe ou em diferentes contextos de trabalho, confirmando que o professor é um sujeito hermenêutico porque vivencia o desafio de produzir sentidos. Neste entorno é que se diz que ele é um mediador de saberes e que sua prática é reflexiva e transformadora(5).

\section{METODOLOGIA}

Como definição de seu traçado metodológico, o estudo desenvolveu-se dentro da abordagem qualitativa, por levar à descoberta de significados, para o que utilizamos estratégias como entrevistas, que propiciam ao pesquisador explorar as experiências das pessoas, buscando saber como vêem e como se sentem quando defrontadas com as situações estudadas ${ }^{(7)}$. Igualmente, caracteriza-se como uma abordagem que permite mostrar a perspectiva dos participantes a partir de diversas opiniões, valores, crenças, atitudes e emoções( ${ }^{(8)}$.

Dentro do enfoque da metodologia qualitativa optamos pela abordagem da História Oral em virtude de seus estreitos laços com a educação e na consideração de que não se caracterize somente como uma metodologia, uma técnica de escolha de dados ou mesmo uma fonte, como é comum encontrá-la definida muitas vezes.

O cenário da pesquisa foi o Departamento de Enfermagem da UFPI e os sujeitos de investigação 10 (dez) professoras do Curso de Enfermagem da UFPI, todas vinculadas oficialmente ao Centro de Ciências da Saúde (CCS) e na condição de professoras efetivas. Todas, no momento, ministram aula nos $5^{\circ}$ e $6^{\circ}$ períodos do curso em referência, por entendermos que, nesses períodos, as disciplinas, majoritariamente, são específicas e teórico-práticas e, em geral, agregam revisões teóricas, estágios supervisionados e são ministradas somente por docentes enfermeiras.

O principal (e também o único) instrumento de recolha de dados empregado na presente pesquisa foi à entrevista semi estruturada, sobretudo por entendermos que entrevistar é estabelecer uma relação comunicativa, a qual está presente em todas as formas de coleta dos dados orais, implicando sempre um colóquio entre o pesquisador e o narrador ${ }^{(9)}$.

A etapa dedicada à coleta de dados começou no mês de setembro de 2005, com término no mês de abril de 2006, portanto, com duração de 07 (sete) meses. Antes de iniciar a entrevista, apresentamos os objetivos do 
estudo aos sujeitos e solicitamos seu consentimento para realizar a entrevista, gravá-la e divulgar os resultados.

Para proceder à análise de dados, empregamos a técnica de análise de conteúdo ${ }^{(10)}$, que a define como um conjunto de técnicas de comunicação e que não são rigorosamente definidas nem inflexíveis.

Foi solicitado o Termo de Consentimento junto aos sujeitos participantes do estudo, levando em consideração os aspectos éticos propostos pela Resolução 196/1996, do Conselho Nacional de Saúde, sobre pesquisas envolvendo seres humanos e a prévia autorização dos responsáveis pela instituição onde será realizada a pesquisa ${ }^{(11)}$.

\section{ANÁLISE DOS RESULTADOS}

A narrativa de si por meio da História Oral nos faz adentrar em territórios existenciais, em significados construídos/desconstruídos sobre a docência, bem como no que diz respeito às aprendizagens construídas. A partir das categorias e iniciado o trabalho de análise, fomos constatando a importância do trabalho com memórias reconstruídas através da História Oral das professoras. Trata-se de significações que se explicitam por meio da evocação de lembranças distantes e de lembranças mais próximas, evocações como das professoras sobre como desenvolvem sua prática pedagógica e de como elaboram os saberes que dão sustentação ao fazer docente.

Assim, a partir das falas dos sujeitos foi possivvel obter uma aproximação significativa entre as histórias das docentes e os relatos orais, favorecendo conhecer a trajetória e as significações construídas no interior da prática pedagógica, pois a memória revela a magnitude da dimensão pessoal e profissional que essas professoras carregam nessas histórias.

De modo que os dados obtidos delinearam a presente árvore categorial, a partir da qual as narrativas das professoras/parceiras foram agrupadas em blocos de falas que, conforme seu sentido explícito ou implícito, sua natureza e peculiaridades, suscitam a emergência de categorias.

A árvore categorial assim se compõe: Categoria 1: A construção da prática de ensinar: o que dizem as professoras do curso de enfermagem; Categoria 2: O significado da prática docente na constituição do saber ensinar das professoras; e Categoria 3: Os Saberes da docência como fundamento da prática pedagógica no curso de enfermagem.

Constatamos nesta pesquisa, na voz das interlocutoras, que os saberes são importantes tanto nos processos formativos, e atuação profissional, como enquanto fatores que possibilitam a projeção da imagem da/na docência, bem como caracterizam a prática pedagógica dos professores. Nessa perspectiva, as professoras parceiras desta investigação acreditam que a continuidade da formação é indispensável para a consolidação profissional, tendo em vista atender satisfatoriamente as necessidades impostas pelo atual contexto educacional. Partem da compreensão de que essa formação se constrói ao longo da carreira docente, desde que seu exercício seja comprometido com a profissão, com a articulação dos saberes e das práticas pedagógicas, visando à melhoria do ensino e da aprendizagem de seus alunos.

\section{Categoria 01: A construção da prática de ensinar: o que dizem as professoras do curso de enfermagem}

As reflexões realizadas pelas professoras interlocutoras em relação à construção de suas práticas de ensinar mostraram que, no desempenho das atividades de ensino no Curso de Enfermagem, há compromisso e envolvimento com esse trabalho, aliando a essa compreensão a visão de complexidade que, no geral, marca o processo ensino-aprendizagem.

As professoras do Curso de Enfermagem relatam como desenvolvem a sua prática diária e quais ferramentas educativas utilizam. As professoras ao se defrontarem com os problemas da sala de aula, que, a rigor, são bastante complexos, lançam mão de um conhecimento profissional construído na vivência da prática pedagógica, tomando como ponto de partida a gestão do conteúdo e os conhecimentos prévios dos alunos, de forma original e, muitas vezes, de forma criativa, elaborando sua própria maneira de atuação na sala de aula.

As narrativas das professoras revelam os elementos necessários à prática pedagógica (saber-ser e saber-fazer). Expressam que o professor, além de conduzir de forma competente a gestão pedagógica e disciplinar da sala de aula, para exercer o ofício de ensinar, necessita, entre outras coisas, conhecer os alunos. Aesse respeito, reporta-se aos elementos que compõem a base de conhecimentos para a docência, isto é, a um conhecimento que dá conta, no âmbito da prática docente, dos conteúdos das disciplinas curriculares, ou seja, refere-se ao conhecimento da matéria que leciona ${ }^{(12)}$. Agregados a este tipo de conhecimento, necessariamente, estão: o conhecimento pedagógico geral (processo pedagógico, motivação, estilos de aprendizagem e etc.); o conhecimento curricular; o conhecimento dos fins e metas da educação e dos contextos educacionais, e, finalmente, o conhecimento dos alunos, de seus específicos estilos de aprendizagem.

É importante também verificar que nessa condução de reflexões em torno da prática pedagógica, a postura das professoras parece contribuir para que os alunos repensem suas incertezas e as visões consolidadas, exercício que dificilmente fariam sozinhos. Desse modo, ao refletir acerca desta questão, apontam a importância que o diálogo representa um instrumento, por excelência, do professor para possibilitar a produção de conhecimentos em sala de aula ${ }^{(13)}$. Entendemos, pois, ser importante valorizar sempre a realidade do aluno, seu universo e o conhecimento que traz de seu grupo social, contribuindo com seu processo de sentir-se sujeito do mundo escolar mediante uma didática contextualizada/ressignificada.

Ainda considerando acerca desta categoria, as professoras interlocutoras, analisando o desenvolvimento da prática pedagógica, afirmaram que como procedimentos metodológicos, usualmente, costumam privilegiar aulas expositivas e de demonstrações ${ }^{1}$, oportunizando momentos do aprender fazendo, bem como enfatizando a troca de saberes entre professora e alunos.

\section{Categoria 2: 0 significado da prática docente na constituição do} saber ensinar das professoras do curso de enfermagem

0 exercício da docência exige não só um amplo lastro de saberes diversificados, mas, sobremaneira, uma aprendizagem contínua, considerada pelas professoras do Curso de Enfermagem como fundamental na carreira profissional, alicerçada pelo aporte de saberes do professor, como arranjo de uma arte específica que identifica um ofício mediado pela teoria e pela prática, que vem a ser a compreensão do saber ensinar do professor de profissão.

A formação de professores é um processo contínuo, cujo desenvolvimento se estende ao longo do percurso da carreira profissional, de tal modo que 0 desenvolvimento envolve uma aprendizagem contínua, interativa, acumulativa, que combina uma variedade de formatos de aprendizagem ${ }^{(14)}$. A formação de professores visa contribuir para que os docentes se formem como sujeitos, e, como tal, percebam sua responsabilidade no desenvolvimento da escola, do ensino e da aprendizagem, demonstrando atitude ativa e reflexiva sobre a prática pedagógica que desenvolvem e que, simultaneamente, estão oferecendo à comunidade escolar.

Assim, a necessidade de uma formação específica passa, também, pela iniciativa das professoras ao defenderem a busca de conhecimentos através de cursos de formação continuada, trocas de experiências entre os pares, preparo teórico e instrumental para atuar em sala de aula, cursos de atualização.

Os saberes pedagógicos são considerados essenciais pelas professoras. No seu caminhar docente, aborda a necessidade do conhecimento, ou seja, da diferenciação entre saber e conhecimento emerge a importância do saber pedagógico - enquanto saber construído pelo professor no exercício da docência - como elemento que contribui para uma nova leitura da (des)qualificação docente, pois mostra a atividade do professor como uma atividade que demanda uma capacidade que vai além da execução, uma atividade de grande relevância na condução do processo educacional que vise a um ensino de qualidade. Como fase do desenvolvimento, o saber pedagógico, enquanto expressão da atividade do professor indica o nível da práxis em que se situa ${ }^{(15)}$. 
A atividade docente é considerada como expressão do saber pedagógico e este, ao mesmo tempo, fundamento e produto da atividade docente que acontece no contexto escolar, numa instituição social e historicamente construída. Estamos dizendo que o trabalho docente é uma prática social. Prática que se faz no cotidiano dos sujeitos nela envolvidos, e que, portanto, nela se constituem como seres humanos. Assim, a prática docente, expressão do saber pedagógico, constitui-se numa fonte de desenvolvimento da teoria pedagógica. As necessidades práticas que emergem do cotidiano da sala de aula demandam uma teoria ${ }^{(15)}$.

A pesquisa evidenciou a importância dos saberes da experiência que reside no fato de que eles podem funcionar como um "filtro" dos outros saberes, possibilitando uma re-visão e uma re-avaliação dos saberes adquiridos anteriormente e exteriormente à prática profissional propriamente dita. E, sendo assim, podem promover a emergência e consolidação de um "novo" saber, um saber formado de todos os saberes retraduzidos e submetido ao processo de validação constituído pela prática cotidiana.

Como encaminhamento conclusivo das análises desenvolvidas nesta categoria, observamos que, com relação à necessidade de uma especificidade de formação para a docência, não se evidenciou um movimento linear em todas as narrativas expressas. No entanto, é visivel a modificação, o crescimento da formação dessas professoras que, sem dúvida, estão construindo a sua própria história, mesmo que, em alguns casos, diante de condições adversas ${ }^{(16)}$. Observamos, pois, que o prazer de aprender, associado à consciência da responsabilidade que assumiram ao optar pela docência, é um dado que revela seu compromisso e seriedade com a sua tarefa profissional docente.

\section{Categoria 3: os saberes da docência como fundamento da prática pedagógica no curso de enfermagem}

Nessa categoria as professoras identificam que na sua prática pedagógica trabalham os saberes com vistas a um melhor aprendizado para o aluno.

Os saberes docentes são reconhecidos pelas professoras, nossas interlocutoras, quando exercidos em sua plenitude no espaço das escolas que lhe garantam espaço e tempo contextualizados à realidade social que as circundam. Os mesmos visam à construção de conhecimentos acrescidos de complexas experiências geradoras de novos conhecimentos atendendo a especificidades próprias do ensino-aprendizagem.

Considera-se que os saberes docentes são fortemente influenciados pela questão do tempo. Sendo os saberes estruturas mutantes, elas amadurecem com o passar do tempo. Na análise observamos que o tempo de atuação profissional é um importante fator na construção e mobilização dos saberes, aliado também a uma prática de trabalho coletivo e colaborativo que permeia a instalação de um permanente estado de reflexão sobre e na prática cotidiana. A docência é complexa, ela depende dos saberes da área que trazemos e dos saberes da profissão, também os estudos, os conhecimentos, as especializações possibilitam o aprofundar de nossa área específica.

0 que percebemos nas narrativas das professoras do curso de enfermagem, é que, na grande maioria, o docente enfermeiro tem formação específica, a partir de uma concepção técnico-científica de ser humano e de mundo, a partir daí, passa a conviver no cotidiano da sala de aula com anseios e expectativas incomuns em relação à prática da enfermagem. As docentes têm consciência de que, neste momento, encontram-se em uma sociedade rodeada de certezas tecnológicas, de verdade e tradição, também, o que, necessariamente, aponta para a necessidade de uma formação pedagógica, complementadora de formação da enfermagem, como forma de tornar-se uma melhor professora, como forma de melhor exercer, viver, a docência universitária no curso de enfermagem.

A constituição de escolas de enfermagem se deu de acordo com interesses em capacitação de mão-de-obra hospitalar. Entretanto, a saúde e a enfermagem, com o passar do tempo, sempre foram direcionadas para a afirmação de modelo médico-hospitalar de alta tecnologia e alto custo.

$\mathrm{Na}$ enfermagem, precisamos de conhecimentos que permitam reestruturação que sejam úteis ao ser humano e à sociedade; não conhecimentos imutáveis e inquestionáveis. Precisamos desenvolver outras e novas características nos professores e alunos, para que sejam capazes de enfrentar as adversidades do mundo atual. $\mathrm{O}$ ato de educar deve ser contínuo e construído por alunos e professores, de maneira criativa e inovadora. $O$ aluno é parte essencial e integrante do processo educativo, com o que compartilhamos plenamente e, na mesma proporção, colocamos o professor, sua formação, seus saberes, e suas práticas ${ }^{(13,17)}$. Não há como promover mudanças se os docentes em Enfermagem ainda estão presos ao sistema de reprodução do conhecimento, tal como nos primórdios da enfermagem. $A$ necessidade de construir uma nova idéia de professor pode ser mais ou menos consciente. Isso porque, a pressão que o professor recebe da sociedade o impulsiona para a reflexão ou para a tomada de consciência de repensar a prática docente ${ }^{(16)}$

Assim, retomamos a revisão da literatura ${ }^{(18)}$ que vê a formação como possibilidade de estímulo a uma perspectiva crítico-reflexiva, como forma de exercitar um pensamento autônomo, em particular no que se refere a sua prática pedagógica, ou mesmo ao afirmar que a prática pedagógica, diante de um paradigma inovador, estimula o professor a sentir-se desafiado, a ver 0 seu entorno com mais amplitude, como perspectiva à superação de um conhecimento estático, de práticas pedagógicas rotineiras, enfim, "produzindo" e vivenciando uma prática pedagógica intencional e problematizadora, como decorrência, do processo formativo ${ }^{(17)}$.

Nessa categoria se expressa que a atividade docente não se exerce sobre um objeto, sobre um fenômeno a ser conhecido, ou uma obra a ser produzida, isto é, ela se desdobra concretamente numa rede de interações com outras pessoas, num contexto onde o elemento humano é determinante e dominante.

O saber proporcionado pela prática é valorizado pelas professoras, mas não é interpretado como suficiente para dotá-las das habilidades requeridas ao exercício de sua profissão. Por isso, esses saberes não podem se acomodar ao controle autoritário da prática cotidiana de sala de aula, nem, tampouco, arcar os conhecimentos teóricos como instrumentos de natureza normativa, a serem aplicados de forma imediata. A formação de professores inclui, pois, os saberes adquiridos na prática, mas, também, a aquisição e a elaboração de outros saberes que integram, vamos dizer, a base teórica sólida, com a qual deve contar todo professor.

Neste estudo trabalhamos com os depoimentos orais das professoras, isto é, com narrativas específicas sobre as práticas pedagógicas por elas desenvolvidas e, nessa prática, a conexão com os saberes. As professorasinterlocutoras manifestaram suas idéias sobre os saberes originados em suas práticas diárias, dos saberes curriculares e de sua formação, eapontaram que os conhecimentos pedagógicos necessitam ser construídos e reconstruídos em função de um movimento educativo em permanentes transformações.

\section{CONSIDERAÇÕES FINAIS}

No estudo desenvolvido, foi possivel obter evidências de que os saberes das professoras estão em permanente construção e decorrem, em grande parte, das influências geradas pela sua história, pela sua formação universitária, pelas experiências profissionais vividas na escola e pelas interações com outros professores no exercício profissional, o que corrobora o entendimento de que o movimento de avanço da reflexão sobre o ser professor deve ser necessário e contínuo, assim como a busca de caminhos inovadores e de novos contornos à prática pedagógica do enfermeiro-professor, que sabemos ser um processo de construção e reconstrução.

Desse modo, a formação do professor possibilita uma prática pedagógica atual, contextualizada, preocupada com o contexto sócio-político-cultural com vistas às transformações da sociedade indo ao encontro das Diretrizes Curriculares do curso de enfermagem, que procuram assegurar a flexibilidade, a diversidade e a qualidade do ensino oferecido ao aluno, estimulando a 
adoção de concepções que visem ao desenvolvimento da prática investigativa nas diversas áreas de atuação (assistência, ensino, pesquisa e extensão), configurando a compreensão de que professor e aluno são sujeitos ativos do processo ensino-aprendizagem e, ao mesmo tempo, em conformidade com os preceitos do SUS que alberga a assistência do paciente como sujeito ativo na assistência do cuidar, respeitando a singularidade e individualidade de cada ser humano.
Assim, uma significativa constatação desta pesquisa considerando uma dimensão triangular articulada, que envolve a formação do professor, a prática pedagógica e os saberes docentes das professoras de enfermagem, é que a formação é continuada. No cotidiano da prática pedagógica, os saberes docentes são adquiridos, processados, reprocessados e difundidos, de maneira que, nessa dialeticidade, esses saberes favorecem também a formação. Favorecem a compreensão do tornar-se professor de profissão.

\section{REFERÊNCIAS}

1. Perrenoud P. Práticas pedagógicas, profissão docente e formação: perspectivas sociológicas. Lisboa (POR): Dom Quixote; 1993.

2. Bagnato MHS. Fazendo a travessia: em pauta a formação dos profissionais da área da saúde. In: Bagnato MHS, Cocco, MIM Sordi MRL, organizadores. Educação, saúde e trabalho: antigos problemas, novos contextos, outros olhares. Campinas (SP): Alínea; 1999

3. Tardif M. Saberes docentes e formação profissional. Petrópolis, (RJ): Vozes; 2002.

4. Tardif M. 0 saber social da prática docente (monografia). Fortaleza (CE): Faculdade de Educação/Universidade Federal do Ceará; 1993.

5. Therrien J. $O$ saber do trabalho docente e a formação do professor. In: Anais do I Congresso Ibero-americano de Formação de professores. Santa Maria (RS); Brasil; 2000. Santa Maria (RS): UFSM; 2000.

6. Gauthier C. Por uma teoria da pedagogia: pesquisas contemporâneas sobre o saber docente. ljuí (RS): UNIJUÍ; 1998.

7. Polit DF, Hungler BP. Fundamentos de pesquisa em enfermagem

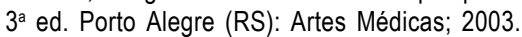

8. Lüdke M, André MED. A. Pesquisa em educação: abordagens qualitativas. São Paulo (SP): EPU; 1986.

9. Minayo MCS. Pesquisa social: teoria, método e criatividade. $21^{\text {a }}$ ed. Petrópolis (RJ): Vozes; 1994.

10. Bardin L. Análise de conteúdo. Lisboa (POR): Edições 70; 1979.

11. Ministério da Saúde (BR). Conselho Nacional de Saúde. Resolução no 196/96. Diretrizes e Normas Regulamentadoras de Pesquisa Envolvendo Seres Humanos. Informe Epidemiológico do SUS 1996;5(2):17-41.

12. Fiorentini D, Souza JR AJ, Melo AGF. Saberes docentes: um desafio para acadêmicos e práticos. In: Geraldi CMG, Fiorentini D, Pereira EMA. Cartografia do trabalho docente: professor (a)pesquisador (a). $3^{\text {a }}$ ed. Campinas (SP): Mercado de Letras; 2003.

13. Freire $P$. Pedagogia da autonomia: saberes necessários à prática educativa. São Paulo (SP): Paz e Terra; 1996.

14. Gárcia MC. Formação de professores: para uma mudança educativa. Porto (POR): Porto Editora; 1999.

15. Pimenta SG. Saberes Pedagógicos e atividade docente. $4^{\mathrm{a}}$ ed. São Paulo (SP): Cortez; 2005.

16. Cunha Ml. O professor universitário na transição de paradigmas. Araraquara (SP): JM Editora; 1998.

17. Behrens MA. O paradigma emergente e a prática pedagógica. Curitiba (PR): Champagnat; 2003.

18. Nóvoa A. Vidas de professores. $2^{2}$ ed. Porto (POR): Porto Editora; 1992. 